\title{
Los Restos del Inca Garcilaso
}

\author{
por Raúl Porras Barkenechea
}

El 18 de Setiembre de 1612 el Inca Garcilaso de la Vega, vecino de Córdoba, compró en la Iglesia Catedral de esa ciudad un arco y capilla en el lado llamado de los Naranjos en frente del Altar Mayor, para que le sirviera de entierro. El Inca septuagenario - que acaba de publicar la Primera Parte de los Comentarios Reales y se ocupaba empeñosamente en terminar de copiar e imprimir la Segunda Parte- se comprometió a hacer un retablo y reja de hierro en la capilla y un soldado de ladrillo en toda la nave, desde la capilla al Altar Mayor. La capilla le fué cedida, para él y sus sucesores, con "dos sepulturas terrisas que ha de hacer a la linde y junto de la capilla".

En cumplimiento decsu contrato el Inca, vecino entonces de la colación de Santa María, mandó hacer al cerrajero Gaspar Martines una reja de hierro "con sus puertas y cerraja y quizialero y cerrojo" de buen hierro, que fuera "media vara mas alta que la de la capilla del jurado Martin Gomez", y al escultor Felipe Basques de Vreta "un Cristo de madera de pino, crucificado".

En su testamento de 18 de Abril de 1616, dictado cinco días antes de morir, el Inca ordena ser sepultado "en la Iglesia Catedral de Cordoba en la capilla que yo e rredificado que se dize de las Benditas Animas de Purgatorio" (1). El Inca declara que él ha escogido esta advocación y ordena que se digan en ese recinto todas las misas que se puedan decir por su alma y las ánimas del purgatorio. La víspera del día de Todos los Santos de-

(1) De la Torre y del Cerro, José: El Inca Garcilaso de la Vega (Nueva Documentación). Madrid, 1935, p. 182. 
bería celebrarse en la tarde una vigilia cantada y en la mañana siguiente una misa de requiem cantada, poniendo una tumba con un paño negro con sus candeleros y doce cirios ardiendo. Nombró patrón y perpetuo administrador de la Capilla al Dean y Cabildo de la santa Iglesia de Córdoba en cabildo pleno y a don Francisco de Corral, caballero de la Orden de Santiago y veinticuatro de Córdoba (2). Un sacristán conservaría siempre limpios los ornamentos y aderezado el altar y sobre él ardería siempre, de día y de noche, una lámpara de manera que estuviese prendida perpetuamente. En un rasgo de benevolencia dispuso el In$\mathrm{ca}$, por último, que se pudiesen enterrar en su capilla, previo consentimiento de los patronos de ella, algún canónigo o beneficiario de la Iglesia de Córdoba o algún Inquisidor, fiscal o juez de bienes y también el clérigo y licenciado Antonio de Cea. Agravando su condescendencia ordenó en su primer codicilo que se pudiesen enterrar también en el suelo de la capilla Miguel de Herrera, vecino de Córdoba, su mujer Beatriz de Ribera y sus parientes Alonso, Sebastián y Francisco/de Herrera; pero en el tercer codicilo dispuso que no To fueran en "el hueco de la capilla", sino en las sepulturas terrizas de fuera. La bóveda quedó así resevada para él y sus amigos eclesiásticos. Para sus criados y para Juan Chamico Garrido, ministril de la Iglesia de Córdoba, cedió "las tres sepulturas terrizas" que había adquirido antes en la nave de la Iglesia fueráde la capilla. Nómbró, por último, herederos de sus censos y hacienda a su alma y a las ánimas del Purgatorio y como beneficiaria terrena a su Capilla de la Catedral, que resultó así, a la postre, su última y universal heredera.

De conformidad con estas disposiciones, dictadas por el Inca en su vencida ancianidad y resignado a su destino de descendiente de los Incas - a quien no le fué dado volver al Perú y al Cuzco su ciudad bienamada, en la que hubiera querido descansar finalmente-, los restos de Garcilaso han reposado en la oscura Capilla de las Animas de la mezquita de Córdoba, durante más de tres siglos, en un prolongado anonimato. Las Guías de Córdoba dedicadas a revivir el pasado español de la capital del Califato árabe, exaltaron naturalmente las excelsas figuras cordo-

(2) "Lo que el Cabildo dijere, hordenare y determinaren los dichos señores Dean e Cabildo, habría de pasarse por ello" (Quinto y último codicilo). 
besas de las letras, las artes, la política o la guerra-Séneca, Lucano. Góngora, el Gran Capitán-i prescindiendo siemure de mencionor siquiera al olvidado huésped de la capilla de las Animas, al excelso escritor mestizo de América que escribió en los Comentarios Reales la epopeya india y española del Perú. Garcilaso continuó soportando pues, póstumamente, como muerto anónimo y desdeñado en la Catedral de Córdoba, la misma posición humilde y desarraigada que llevó en su vida terrena, que discurrió en Córdoba según su propia afirmación por "los rincones de la soledad y de la pobreza". Dejaron de decirse las misas por su alma, establecidas por su testamento, y de arder la lámpara perenne en la Capilla de las Animas. De vez en cuando un turista peruano $\circ$ un investigador extranjero llegaba hasta las puertas de la Capilla para leer las inscripciones doradas sobre las lápidas negras que se hallan en su interior y que dicen:

El Inca Garcilaso / de la Vega, varon insig-/ ne, digno de perpetua / memoria illustre en sangre / perito en letras, valien/ te en armas, hijo de / Garcilaso de la Vega / de las casas de los Duques de Feria e Infan / tado, y de Elisabeth / Palla hermana de / Huayna Capac vlti / mo Emperador de / Indias. Comentó la / Florida, traduxo a / Leon Hebreo, y compu / so los comentarios reales.

Viuio en Bordóf tuaccon mucha religs / on, murio exemplar,/ dotó esta capilla, en / terrose en ella, yincu / ló sus bienes al su/ fragio de las animas/ de purgatorio, son / Patronos perpetu /os los los señores De-/ an, y Cabildo desta / Santa Yglesia. Falle-/ ció a veynte y dos / de Abril de mil y se- /yscientos y diez y seis / Rueguen a Dios por su / Anima.

Corno un gesto tardío, benévolo y original, un profesor británico de la Universidad de Cambridge, admirador silencioso y remoto del Inca, Mr. Bullock, del Queen's College, ofreció al Cabildo de la Catedral cordobesa pagar de su peculio, como lo hace periódicamente, el mantenimiento de la lámpara recordatoria sobre la tumba del Inca Garcilaso.

En 1948, al ser designado Embajador del Perú en España, propuse al ilustrado Gobierno del doctor José Luis Bustamante y Rivero -que me nombrara-, solicitar del Gobierno Español, como una forma de reparar el olvido en que yace la memoria del Inca en la mezquita cordobesa y su proscripción forzada, en la vida y en la muerte, de la Imperial metrópoli hispano-india en que naciera, la 
"gran ciudad del Cuzco, cabeza de todas las ciudades del Perú", la repatriación de sus restos para que reposaran finalmente en su Iglesia Catedral, restaurada por España y en la que recibiría mejor que en Córdoba el homenaje de los indios del Cuzco y sus compatriotas todos del Perú. En ella sería el signo permanente de la fraternidad entre ambos pueblos, en un reencuentro anhelado después de largos siglos de proscripción y silencio.

En virtud de la autorización recibida del Gobierno del Perú, inicié las gestiones ante el Jefe del Estado Español y el Ministerio de Asuntos Extranjeros, contestándoseme que el Gobierno no tendría inconveniente en esa repatriación, siempre que se obluviese la autorización de las instituciones u organismos de quienes dependiera la conservación de los restos. De conformidad con el testamento de Garcilaso la tutela jurídica de éstos, por delegación de la voluntad del Inca, corresponde al Dean y Cabildo de Córdoba. De ahí que apenas presentadas mis credenciales como Embajador y reconocido. en mi calidad de tal, me trasladé en compañía, del Director de Bellas Aries y finísimo escritor y crítico de arte, inmejorable amigo del Perú, don Juan de Contreras y Lozoya, Marqués de Lozoya, y del Ministro Consejero de la Embajada, don Manuel Mujica Gallo, a visitar la tumba de Garcilaso e Identificar los restos de éste sepultos bajo la bóveda ignota de la Capilla de las Animas.

Nuestra visita a la tumba de Garcilaso el 14 de Enero de 1949 y la identificación de los restos de Garcilaso, confundidos en la bóveda con otros sepultados ahí ilícitamente, se hallan descritos en el informe elevado a la Cancillería del Perú. Las gestiones que entonces hice para obtener la repatriación se hallaban, al producirse mi separación de la Embajada, en Setiembre de 1949, virtualmente culminadas. El cultísimo Obispo de Córdoba don Albino Menéndez Raigada, escritor y orador insigne, gran propulsor de obras sociales y conocedor de América y el Dean del Cabildo, espíritu noble, humano y comprensivo, accedieron a mi pedido, después de escuchadas las razones que expuse sobre la situación de fuerza que obligó al Inca a recluirse y morir en Córdoba, impedido de volver al Perú, por orden real; el abandono actual, de la capilla, falta de cumplimiento involuntario de las cláusulas del testamento y el clamor peruano por la restitución de los restos de su escritor más representativo y olvidado huésped de la mezquita de Córdoba. Determinaron también esa decistón los ofrecl- 
mientos que hice formalmente de atender a todas las mandas religiosas establecidas por el Inca en su capilla, en la que se seguiría orando por él y cumpliendo sus devotas disposiciones en favor de su alma y de las ánimas benditas y, además, el propósito que les manifesté de hacer visible y palpable el recuerdo del Inca en Córdoba por la dotación que haría el Gobierno del Perú a una escuela para niños pobres en la casa que el Inca habitó en la calle del Dean, de esa ciudad. Estas proposiciones fueron acogidas con amplio e hidalgo espíritu y el Cabildo de la Iglesia Catedral adoptó el siguiente acuerdo, que por primera vez se reproduce, y es en verdad el acto de devolución de los restos de Garcilaso, ya que el Cabildo es el depositario jurídico de los restos y de la voluntad del Inca, pues éste dijo en su postrimera decisión que se pasase "por lo que el Dean e Cabildo dijere, hordenare e determinare". El voto del Cabildo -que es jurídicamente decisivo, dada la voluntad de respetarlo del Gobierno Español-, coincide con el íntimo anhelo incumplido de Garcilaso de volver al Cuzco, tantas veces expresado, y coincide con el del pueblo peruano de obtener esos despojos humanos que son esencialmente suyos.

El acuerdo del Cabildo es éste:

"Acuerdo final del día 18 de Enero de 1949._- "El Excmo. Cabildo, en principioi no se opondría, al llegar el momento, al traslado a la República del Perú de los restos del Inca Garcilaso de la Vega, servalis omnibus de jure servandis, a pesar del sacrificio que supone para esta Excma. Corporación dejar de ser custodio en la Santa Iglesia Catedral de los restos de tan ilustre clérigo, que demostró en su vida y en su última voluntad tenerle tanto cariño y devoción. Entretanto, el Muy Ilustre Sr. Dean, oficiosamente y de palabra, continuará relacionándose con los Sres. que al Excmo. Sr. Obispo se han dirigido, y de todo cuanto se venga conociendo dará cuenta al Excmo. Cabildo".

Obtenida la aprobación cardinal del Cabildo debía consultarse desde un punto de vista técnico o protocolario a la Academia de la Historia de Madrid, a la Dirección de Bellas Artes, al Ayuntamiento de Córdoba, a la Academia de Ciencias, Bellas Letras y Nobles Artes de Córdoba. El Director de la Academia de la Historia, el Excmo. Sr. Jacobo Fitz James, Duque de Alba, manifestó no sólo su aprobación sino su simpatía para un acto que no podía sino reafirmar los vínculos espirituales entre el Perú y España y me 
expresó que su dictamen sería favorable. El Marqués de Lozoya, exaltador de la Ciudad del Cuzco y del pasado indio de Machu Picchu, declaró también su apoyo por esta iniciativa de reintegración al Cuzco de sus valores espirituales históricos que reafirman su vinculación con la hispanidad. En cambio hubo algunas voces disonantes, como fruto de una divergencia entre organismos y jerarquías regionales, más que como disentimiento o falta de amistad hacia el Perú, en los sectores del Ayuntamiento y en los académicos, que se reflejaron en algunos artículos periodísticos. Estas lógicas resistencias, en el momento preliminar, estoy seguro de que hubieran sido superadas, tanto por la consideración de los hondos motivos nacionales y espirituales que sustentan la demanda del pueblo peruano, como por la natural hidalguía de los opositores que habrían considerado, al fin, que la repatriación de los restos honraría permanentemente a la antigua metrópoli, en la urbe indiana y en su catedral hispánica, donde sería acicate de respeto $\mathrm{y}$ veneración para los indios. Muestra de ese espíritu hallo en la benévola y honrosísima designación que me hizo la Academia de Córdoba del título de miembro honorario de ella y la invitación que hice para asistir al Congreso de Peruanistas de 1951 al ilustre garcilasista cordobés don José de la Torre y del Cerro, miembro de aquella docta Academia, quien fué aclamado en la sesión plenaria de dicho Congreso al votarse, con su concurso, la moción que pedía a nombre de todos los americanistas el retorno de los restos del đnca despuése de Sunlágo oy forzado destierro.

Posteriormente, el Primer Congreso Nacional de Historia reunido en Lima, en 1954, ratificó el anhela de que vuelvan a su patria cuzqueña los restos del Inca historiador.

La más sugestiva nota de esta reclamación diplomática romántica y significativa, fué el reflejo que ella encontró en la límpida prosa del periodista don José M. Pérez Torreblanca, quien en un breve y armonioso comentario de media columna en el vespertino "La Tarde" de Madrid, relievó la significación de mi visita a la tumba de Garcilaso, después de presentar credenciales ante el Gobierno Español, titulándolo Credenciales ante un capitán dormido.

Por último, el Ministerio de Relaciones Exteriores del Perú, del nuevo gobierno instalado en Octubre de 1948, me ratificó la aprobación de mis gestiones en la siguiente forma: "La feliz iniciativa 
de Ud. merece la más solícita atención de este Despacho, el que aprueba su prudente proceder, las gestiones confidenciales ya realizadas $y$, en general, todo el plan que Ud., esboza para alcanzar el mejor resultado de este empeño. En consecuencia, queda Ud. autorizado, en la forma más amplia, para oficializar dicha gestión y de antemano el Gobierno aprueba las condiciones que sea necesario cumplir a este efecto, las mismas que Ud. expone en la última parte del oficio a que doy respuesia". Este oficio lleva fecha de 11 de Marzo de 1949. En Setiembre de ese año se dió por terminada mi misión, nombrándose Embajador en España, para el mejor servicio, al Mariscal Don Eloy G. Ureta.

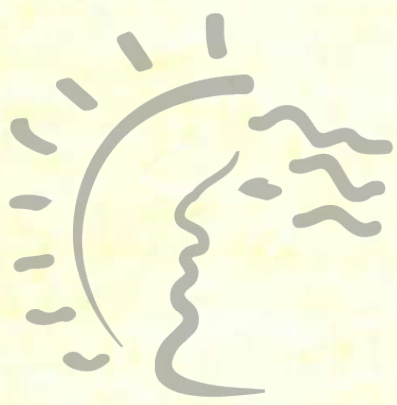

\section{Biblioteca de Letras}

